\title{
Diabetes Mellitus as a Model of Psychosomatic and Somatopsychic Interrelationships
}

\author{
Ludvig I. Wasserman and Elena A. Trifonova \\ V.M. Bekhterev Psychoneurological Research Institute, St.Petersburg, Russia
}

\begin{abstract}
The article reviews research on the problem of interrelationship between different physical and psychosocial factors in type 1 diabetes mellitus (DM1). The authors consider methodological principles of health-related quality of life (HRQoL) assessment in DM1 patients and stress the need for an integrated biopsychosocial approach to the management of the disease. DM1 is a chronic metabolic disease with an absolute requirement for insulin replacement therapy. The stress-inducing nature of DM1 is associated with its unexpected and dramatic manifestation in juvenile years, life-threatening nature of severe hypo-/hyperglycaemias and long-term complications, with the burden of diabetes self-management, threat of work disability, employment and career problems etc. These features of DM1 increase the likelihood of the development of anxiety and depressive disorders, which, in turn, may negatively influence the course of diabetes and in particular, diabetes self-care. This necessitates early diagnosis of emotional and behavioral disturbances in DM1 using self-report instruments as well as clinical assessment. Evidence suggests that active problem-focused coping behavior and adequate social support promote adherence to diabetes regimes and may act as a buffer against negative effects of the disease on HRQoL in DM1 patients. The core element in the HRQoL structure is personal disease picture (as opposed by objective clinical picture) - the cognitive-affectivebehavioral complex reflecting the patient's personal perception of the disease. Examination of the personal disease picture and attitude towards the ailment in DM1 patients may help to improve understanding of the mechanisms of poor adjustment. Problems in disease adjustment can be detected also by diabetes-specific HRQoL assessment. The measures of HRQoL can be applied as screening instruments useful in increasing the effectiveness of patient-provider interactions and diabetes care.

Keywords: diabetes mellitus, psychosocial factors, disease adjustment, health-related quality of life, psychological assessment
\end{abstract}

El artículo revisa la investigación del problema de la interrelación entre diferentes factores físicos y psicosociales en la diabetes melitus tipo 1 (DM1). Los autores consideran los principios de la evaluación de la calidad de vida relacionada con la salud (CVRS) en pacientes de DM1 y ponen de manifiesto la necesidad de un abordaje biopsicosocial integrado del manejo de la enfermedad. La DM1 es una enfermedad metabólica crónica con una necesidad absoluta de terapia de reemplazo de insulina. La naturaleza estresante de la DM1 se asocia con su aparición inesperada y dramática durante los años de juventud, la naturaleza peligrosa de las hipo e hiperglucemias y las complicaciones a largo plazo, con la carga del auto-cuidado de la diabetes, la amenaza de discapacidad laboral, problemas de empleo y carrera, etc. Estas características de la DM1 aumentan la probabilidad de desarrollar trastornos de ansiedad y depresivos que, a su vez, pueden afectar negativamente el curso de la diabetes y, en particular, el auto-cuidado de la diabetes. Esto requiere un diagnóstico temprano de los trastornos emocionales y comportamentales en los enfermos de DM1, empleando instrumentos de auto-informe además de la evaluación clínica. La evidencia sugiere que el comportamiento de afrontamiento activo centrado en los problemas y el apoyo social adecuado promocionan la adherencia a los regímenes diabéticos y pueden amortiguar los efectos negativos de la enfermedad en la CVRS en los pacientes con DM1. El elemento esencial en la estructura de la CVRS es el cuadro clínico personal (en contraste con el cuadro clínico objetivo)— el complejo cognitivo-afectivo-conductual que refleja la percepción personal que tiene el paciente de su enfermedad. El examen del cuadro de enfermedad personal y la actitud hacia la enfermedad en los pacientes con DM1 puede mejorar la comprensión de los mecanismos de desadaptación. Los problemas en la adaptación a la enfermedad también pueden detectarse por medio de la evaluación de la CVRS específica para la diabetes. Las medidas de CVRS pueden aplicarse como instrumentos de criba útiles para incrementar la efectividad de las interacciones paciente-cuidador y del cuidado de la diabetes.

Palabras clave: diabetes melitus, factores psicosociales, adaptación a la enfermedad, calidad de vida relacionada con la salud, evaluación psicológica

Correspondence concerning this article should be addressed to Prof. Ludvig I.Wasserman, Head of Laboratory of Clinical Psychology of V.M. Bekhterev Psychoneurological Research Institute, 193019, St. Petersburg, ul. Bekhtereva 3, Russia. Tel: +7-812- 265-04-44 / 567-71-27. Fax: +7-812- 265-04-44. e-mail: LW@KC5566.spb.edu, wasserman@ bekhterev.org 


\section{Diabetes mellitus as a multidimensional biopsychosocial problem}

Diabetes mellitus (DM) is one of the most relevant issues of contemporary healthcare due to its prevalence (4-5\% of the population in developed countries), its physical and psychosocial consequences for patients (Barrett, 2004), and its economic impact on society (Rubin, Altman, \& Mendelson, 1994). DM is the most widespread incurable endocrine disease associated with absolute or relative insulin deficiency.

A multitude of studies (Delamater et al., 2001; Glasgow, Ruggiero, Eakin, Dryfoos, \& Chobanian, 1997; Glasgow, Toobert, \& Gillette, 2001; Jacobson, de Groot, \& Samson, 1997; Polonsky, 2000) have demonstrated that improvement in health-related quality of life (HRQoL) is unlikely without considering all dimensions of personal functioning: physical, social and undoubtedly, psychological. A comprehensive approach to the person suffering from this disease guarantees greater success in diabetes management and the patient's psychosocial adjustment. However, the effectiveness of such an approach is dependent on the clear comprehension of complex interrelationships between variables of different levels, their cause-effect relations and the development of adequate intervention methods (Wasserman, Gromov, Mikhailov, Lynnik, \& Flerova, 2002). Such comprehension implies an in-depth study of psychosomatic and somatopsychic relationships in DM.

Of prominent importance is the comprehension of the abovementioned interrelationships in Type 1 DM (DM1). The influence of DM1 on HRQoL is determined by the following conditions:

1. DM1 affects principally young people and accompanies the patient throughout the life period of expected highest social activity, in particular in occupation, marital relations, parenting etc. The manifestation of DM1, in contrast to DM2, is usually impetuous and is often associated with hospitalization in critical state. The diagnosis of the disease, bearing in mind the patients' age is usually unexpected and represents a significant psychological trauma for the youths and their family members.

2. DM1 implies a real life threat associated with the development of acute hypo- and hyperglycemic states and long-term complications (diabetic nephropathy, retinopathy, polyneuropathy, autonomic neuropathy etc.).

3. Diabetes complications decrease life expectancy (by $10-30 \%$ ) and its quality, in addition to increasing the risk of disability (in particular blindness, extremity amputation etc.). The adverse consequences of the latter are aggravated by inadequate social protection of disabled persons.

4. DM1 and its complications in particular frequently lead to a decrease in the patient's socioeconomic status, workplace discrimination, and other social difficulties.
5. As a result of the necessity of replacement insulin therapy, DM1 leads to a reorganization of lifestyle and habits. The patient is required to observe the management regimen in order to prevent acute hypoand hyperglycemic states and long-term complications. The diabetes self-care regime includes multiple daily insulin injections, self-adjustment of insulin dosages, blood glucose monitoring, dietary restrictions, additional medication use, and the implementation of specific procedures for the prevention and treatment of diabetic complications, etc.

6. As with any chronic disease, although possibly most pronounced in DM1, the patient has to maintain sustained contact with health-care establishments.

The inability to adjust to the disease results in an unfavorable diabetes course and outcome, rapid incapacitation, and inevitably worsens the patient's social functioning, contributes to stigmatization and disruption of significant relations. Furthermore, it is assumed that the disease has not only physiological (biological) determinants, but also psychosocial contributors. This led to the inclusion of DM in the group of psychosomatic diseases (Alexander, 1950).

At the same time, when the disease is already clinically manifest, that is, an irrevocable fact, somatopsychic relations gain in importance, while psychosomatic relations are characterized by the influence of psychosocial factors on the disease course and outcome. It is necessary to note that, in each individual case, there is no unitary direct causeeffect relation between physical and psychological factors. The nature of the disease and its effect on the patient's HRQoL is determined both by the features of the disease itself and the state/personality characteristics of the patient. DM1 may serve as a graphic model of the mutual influence of psychological and somatic spheres because:

1. It (DM1) gravely influences, although usually not catastrophically, the lifestyle of the patient.

2. In not many other diseases, the prognosis depends to such an extent on the adaptive-compensatory potential of the affected person.

Thus, in DM (and in DM1 in particular), we have to deal with a complex psychosomatic entirety, the comprehension of which is necessary for provision of adequate care.

The conception of DM as a psychosomatic disorder sprouts from the school of psychoanalysis although, in the seventeenth century, the British physician and anatomist Thomas Willis had already noted the link between protracted negative experiences and the development of diabetes (Rubin \& Peyrot, 2002).

Later, a description of personality factors predisposing the person to DM was attempted, that is, the identification of a specific "diabetic personality" (Dunbar, 1948). Researchers have failed to reveal specific personality traits in DM patients (Dunn \& Turtle, 1981). However, the fact that the etiology of the disease is not entirely clear and that the connection between its prevalence and industrialization 
is observed encourages the continuation of the search for DM psychosocial preconditions (Korkina \& Elfimova, 2004). In particular, the fact that emotional arousal by activating sympathetic-adrenergic systems leads to release of catecholamines resulting in an increase of blood glucose level, has served as the basis for research into the role of stress in the development and manifestation of DM.

Empirical findings suggest possible involvement of psychological stress in the pathogenesis of DM, although its mechanisms remain unclear (Wales, 1995).

Data on Type 2 DM (DM2), on the whole, are more demonstrative (Mooy, de Vries, Grootenhuis, Bouter, \& Heine, 2000): In particular, there is evidence that chronic stress and stressful life situations lead to impaired glucose tolerance and an increase in insulin resistance, which are initial symptoms of DM. Depression is considered to be an independent risk factor for DM2, although the nature of this association is not fully explained (Eaton, Armenian, Gallo, Pratt, \& Ford, 1996; Rubin \& Peyrot, 2002). Despite the fact that the significance of stress as an etiological factor in DM1 has not received empirical support, most researchers recognize its ability in conjunction with other factors to precipitate the manifestation of the disease.

It is important to note that the issue of the influence of psychosocial factors on the risk of DM represents a specific aspect of a more general scientific discourse on the so-called "psychosomatic diseases." This category has been excluded from the tenth revision of The International Statistical Classification of Disease and Related Health Problems (ICD10) due to acknowledged role of psychosocial factors in the etiopathogenesis of practically any disease. This underlines the need to study subtle mechanisms of mutual influence of psychological and somatic factors, which form an indivisible entirety at the stage of manifested disease.

The principal somatic factors specific for DM are determined by:

1. Glycemic control (degree of success in maintaining blood glucose levels in the near-normal range).

2. Stability/instability of DM course.

3. Frequency and severity of hypoglycemic states.

4. The degree of hypoglycemia awareness (the ability to identify the first signs of dangerously low blood glucose).

5. Presence/absence and severity of long-term complications (diabetic retinopathy, nephropathy, neuropathy etc.)

6. Features of DM and diabetic complication treatment.

7. Presence/absence and severity of comorbid conditions.

The above-listed factors interact and determine the peculiarity of the clinical picture in each individual DM patient. Furthermore, each of the noted factors interacts with a wide range of other psychosocial factors which in turn are in a state of mutual inter-influence. The following are psychosocial variables that are regarded most important by researchers studying psychosomatic and somatopsychic interrelationships in DM:
1. Depression, anxiety (de Groot, Anderson, Freedland, Clouse, \& Lustman., 2001; Kohen, Burgess, Catalan, \& Lant, 1998), including fear of hypoglycemia (Polonsky, Davis, Jacobson, \& Anderson, 1992), blood-injection related anxiety (Mollema, Snoek, Ader, Heine, \& van der Ploeg, 2001).

2. Other emotional and behavioral disturbances (Jacobson et al., 1997; Wasserman \& Trifonova, 2004).

3. Cognitive impairment (Brands, Biessels, de Haan, Kappelle, \& Kessels, 2005).

4. Stress, stressful life events and circumstances (Surwit \& Schneider, 1993).

5. Coping behavior (Rose, Fliege, Hildebrandt, Schirop, \& Klapp, 2002).

6 . The personal disease picture, personal model of the disease (Skinner \& Hampson, 2001).

7. Personality traits (Rose et al., 2002).

8. Social support, including that of family, family wellbeing (Connell, Davis, Gallant, \& Sharpe, 1994; Glasgow et al., 1997; Skinner, John, \& Hampson, 2000).

9. The quality of patient-health care provider communication. (Glasgow \& Anderson, 1999; Heisler, Bouknight, Hayward, Smith, \& Kerr, 2002).

10. Socio-demographic variables, occupational status, educational level, level of income, diabetes-related disability (Glasgow et al., 1997; Lloyd \& Orchard, 1999).

\section{Psychosocial issues in diabetes mellitus}

The practical significance of examination of the abovementioned factors is determined not only by the possibility of the improvement of HRQoL and psychosocial functioning but also (possibly in first place) by the need to promote behavioral adjustment to the disease, in other words, to encourage adherence to treatment, as DM, and in particular DM1 is a disease, the control of which is practically entirely the onus (95\%, according to the data of Anderson, 1985) of the patient. Fostering of adherence to the diabetes treatment regimen is one of the principal tasks of the psychologist in diabetes care (Harris \& Lustman, 1998) because the life expectancy and quality of life of the patient are closely associated with degree of her/his commitment to self-care.

As noted by Toljamo and Hentinen (2001), and as confirmed by practice, adherence to treatment does not always result in optimal glycemic control. However, failure to perform self-care procedures usually result in metabolic decompensation.

Some patients are unable to reach optimal glycemic control despite their own efforts and the efforts of the medical team. Sometimes these difficulties in adjustment to the illness lead to a significant and persistent metabolic instability with uncontrollable and unpredictable, from the patient's point of view, fluctuations in blood glucose level, 
accompanied by frequent episodes of severe hypo- and/or hyperglycemia (ketoacidosis), resulting in recurrent hospitalizations. Such a course of the disease is referred to as "brittle diabetes." It is most typical of young patients with DM1, especially young women, but can also be observed in DM2 (Schade \& Burge, 1995).

The etiology and mechanisms of brittle DM are not yet thoroughly understood. Comorbid medical conditions, impaired hypoglycemia awareness, insulin resistance, inappropriate secretion of counterregulatory hormones and several other physiological conditions are considered to be of importance. However many researchers emphasize factors of psychosocial nature (Schade \& Burge, 1995; Schade, Eaton, Drumm, \& Duckworth, 1985).

These factors are manifold. Even experienced practitioners are not always able to detect them. It is probable that, the absence of obvious physiological grounds for diabetes "brittleness," or a disproportion of the observed metabolic instability to the revealed physiological causes, should be considered as an evidence of underlying psychosocial determinants (Schade et al., 1985). These may include the patient's inability or reluctance to cooperate with the health-care team, affective disorders, cognitive and behavioral disturbances, factitious disease, stress exceeding the patient's coping ability, manipulative attitudes, etc. One should also consider the possibility of insulin omissions (in particular in women and young patients) in order to attain weight loss, disturbed eating behavior and eating disorders (Herpertz et al., 2000).

In order to reveal specific causes of "psychogenic" brittle DM, it is undoubtedly necessary to carry out a comprehensive psychological examination. Maximum benefit can be achieved from an in-depth psychodiagnostic interview. Such an interview permits an experienced psychologist, well-informed of the problems typical of DM patients, not only to identify targets for psychological interventions, but to clearly formulate aims for additional experimental- psychological investigation. When choosing psychodiagnostic tools in "brittle diabetes cases" it is necessary to take into account the fact that the patient can consciously or otherwise resist psychological intervention, adjust her/his responses, use rigid psychological defenses. Accordingly, the psychologist should consider the possibility of acquiring additional information about the patient (from the physician in charge, close relatives, or friends), and the participation of family members in the psychodiagnostic and psychotherapeutic process. Sometimes the use of projective and semi-projective instruments to reduce the probability of the patient's "insincerity" is justified.

It should be noted that such "difficult" cases in the psychologist's practice are relatively rare. More often, the psychologist is faced with less severe disruptions of compliance, which are, unfortunately, more often the rule than the exception in diabetes-care practice.
In fact, it was the problem of nonadherence that made the health professionals recognize the necessity of cooperation with psychologists and served as impetus for large-scale interdisciplinary research into the mechanisms of the DM patients' adaptation to their ailment.

The results of this inquiry have provided valuable information about the factors affecting the patient's willingness to actively participate in treatment process, cooperate with health-care providers, conform to medical recommendations and perform self-care procedures in order to attain a good diabetic control. In particular, it has been established that the main contributors to nonadherence are:

1. Psychosocial disturbance (Ciechanowski, Katon, \& Russo, 2000; Lustman et al., 2000);

2. Deficit of coping resources and passive coping behavior that impede the overcoming of stress, related or not to the disease (Rose et al., 2002) - "stresscoping" model;

3. Certain features of the personal picture of the disease, as opposed to its objective clinical picture (Skinner \& Hampson, 2001)_-"health beliefs-health behavior" model;

4. Certain features of the patient-physician relationship (Glasgow \& Anderson, 1999).

However, the situation is complicated by the fact that the above-mentioned factors are evidently intertwined, they interact with other psychosocial factors, clinical and socio-demographic features of the individual patient, making the problem of treatment adherence part and parcel of a more general problem of psychosocial adjustment. This fact necessitates a comprehensive investigation, aimed at studying the specifics of psychosomatic and somatopsychic interrelations in every individual patient.

In particular, there are extensive empirical data on the increased risk of anxiety disorders in patients with DM: Generalized anxiety disorders are diagnosed in an average of $14 \%$ of DM patients; sub-clinical anxiety symptoms are manifest in up to $40 \%$ of DM patients as compared to $27 \%$ in the general population (Grigsby, Anderson, Freedland, Clouse, \& Lustman, 2002).

Anxiety of varying severity is typical for practically all disorders of neurotic nature, and therefore indexes of trait and state anxiety can be considered criteria for psychological well-being or otherwise. In DM1 patients, the development of anxiety is intensified by the frustrating and stressful nature of life situations caused by the disease. Anxiety is often associated with the realization of incurable and onerous nature of the disease, its possible unfavorable social consequences (at work, in marital relations etc.), the necessity of change in life-style, and so on.

Anxiety is a natural reaction to the first signs of longterm complications because most patients know or see at times those with severe forms of diabetic complicationsretinopathy, nephropathy, "diabetic foot," etc. Anxiety may 
also be a component of psycho-organic disorders at late stages of the disease.

Anxiety symptoms are frequently accompanied by poor glycemic control and may be erroneously taken for an indication of metabolic instability (Lustman, 1988). The shared autonomic component of anxiety and poor glycemic control significantly complicates differential diagnosis, especially because emotional instability and unstable blood glucose mutually exacerbate each other.

It is however necessary to emphasize that DM is a lifethreatening condition in the long-term (due to complications) and short-term due to acute hypoglycemic states, that is, a decrease in blood glucose to dangerously low levels. The risk of life-threatening hypoglycemia is one that the DM patients have to live with, which may cause a chronic anticipatory anxiety.

Frequent episodes of hypoglycemia have a negative impact on the patient's cognitive functioning, emotional well-being and HRQoL (Northam, Anderson, Werther, Warne, \& Andrewes, 1999; Wredling, Theorell, Roll, Lins, \& Adamson, 1992). Most affected are patients with impaired awareness of hypoglycemia. Unexpected and unmanageable severe hypoglycemia that can occur even at night (the socalled "nocturnal hypoglycemia"), when the patient is alone or in the company of unknown people, may cause the feeling of constant threat and inability to control one's own life. Furthermore, hypoglycemia experienced in the presence of other people may lead to a feeling of embarrassment and guilt which contribute to limitation of personal contacts and social isolation.

As a result, it is of no surprise that in some patients with DM1, severity of hypoglycemia-related worries allows to conclude the occurrence of clinically significant anxiety disorder (F40-F41, F43.2 accordingto ICD-10). Polonsky and colleagues (1992) regard higher levels of trait anxiety, difficulty in differentiating symptoms of anxiety and hypoglycemia, and negative hypoglycemia-related personal experience as the most significant preconditions for development of hypoglycemic fear.

The danger of hypoglycemia-related anxiety disorders lies in that anxiety impedes the recognition of hypoglycemia as it shows with symptoms similar to those of hypoglycemia (tremor, tachycardia, perspiration) that are compensatory responses of the sympathetic nervous system to decreased blood glucose levels. Furthermore, a vicious cycle is formed: frequent hypoglycemia episodes $\rightarrow$ anxiety $\rightarrow$ difficulty in differentiating symptoms of anxiety and hypoglycemia $\rightarrow$ more frequent episodes of hypoglycemia + psychosocial dysfunction + increasing anxiety etc. Fear of hypoglycemia forces the patient to choose the lesser of two evils and to intentionally maintain high blood glucose levels. This in turn contributes to the development and progression of long-term complications, which are an additional source of distress and psychosocial disorders.
Among them, the central position is undoubtedly occupied by depression. It has been documented that, in patients with $\mathrm{DM}$, depression is on average twice as prevalent as in the general population (Anderson, Freedland, Clouse, \& Lustman, 2001; Talbot \& Nouwen, 2000). Furthermore, the risk of depression is greater in persons with poor glycemic control (Lustman et al., 2000) and those affected by diabetic complications (de Groot et al., 2001). Researchers indicate the role of biological, genetic, social, and psychological factors in the development of depressive disorders in DM (Talbot \& Nouwen, 2000). Underscored is the need to regard the comorbid depression an important treatment target. Apart from the increased risk, some researchers (Lustman, Griffith, $\&$ Clouse, 1988) have noted that, on the whole, the course of depression in DM is less favorable than in the absence of chronic somatic comorbidity, with somewhat more protracted depressive episodes and a greater risk of relapses. The cause of this, as with the higher risk of depression in DM, remains unclear and may be related to genetic predisposition, biochemical shifts, and chronic disease-related stress.

Depression being a disorder difficult to treat in itself, when present with somatic comorbidity (and in particular with DM), takes on special significance, as it:

1. Impairs regimen adherence, causing deterioration of metabolic control (Ciechanowski et al., 2000; Lustman et al., 2000);

2. Decreases effectiveness of patient-provider communication (Jackson \& Kroenke, 1999; Katon, 2003);

3. Is directly (independent of regimen adherence) associated with hyperglycemia (Lustman, Clouse, Ciechanowski, Hirsch, \& Freedland, 2005);

4. Increases diabetes-related mortality (Zhang et al., 2005), and the likelihood of microvascular and macrovascular complications and disability (Black, Markides, \& Ray, 2003; Clouse et al., 2003);

5. Decreases the patient's HRQoL (Jacobson et al., 1997; Lustman et al., 2000).

All of the above-mentioned circumstances are links in pathological interrelations causing the exacerbation of psychiatric and somatic disorders. For example, poor treatment adherence in a patient with depressive disorder by increasing specific DM metabolic imbalance worsens the general somatic state of the patient, precipitates the development of long-term complications and may provoke acute hyper- or hypoglycemia and hospitalization, thus increasing stress and inevitably exacerbating affective disorders. Ineffective communication between a depressed patient and health-care providers may contribute to the formation of distorted (mostly negative) subjective conceptions of the disease and treatment, leading to a worsening of the somatic status, feelings of helplessness, hopelessness, and loss of trust in the doctor, etc.

Psychotherapy and psychopharmacological treatment of depression not only relieves the patients of distressing worries, but significantly enhances their general well-being, 
restores normal sleep and eating habits, which are of great importance in DM, improves physical activity, compliance and metabolic control (Lustman \& Clouse, 2002). However, these potential benefits often remain a promise, due to noted underrecognition of depression in persons with DM. In particular, according to Rubin, Ciechanowski, Egede, Lin, and Lustman (2004), early diagnosis and treatment of depression occurs in less that $25 \%$ of cases.

Such circumstances are largely explained by the rising prevalence of masked depressions and somatoform disorders. It is no surprise that the endocrinologist prefers to see in evident autonomic symptoms signs of metabolic decompensation, and in complaints of persistent pain signs of diabetic polyneuropathy, and not of the patient's psychological suffering, especially in view of the fact that one state usually accompanies the other.

As is clear from the above, psychosocial disturbances in DM, and in particular DM1, play a vital role as elements of circular psychosomatic and somatopsychic interrelations. Thus, assessment of severity and clarification of pathogenesis mechanisms of these disorders are obligatory conditions for the prevention of diabetic complications, the optimization of psychosocial functioning and improvement of HRQoL.

Evaluation and treatment of affective disorders acquire particular significance due to the fact that research have presented convincing confirmation of their psychological underlying mechanisms in DM, that is, the possibility to consider their increased prevalence as a result of chronic diabetes-related emotional stress (Talbot, Nouwen, Gingras, Belanger, \& Audet, 1999). In other words, emotional disturbances often represent the affective level of the personal (subjective) disease picture. This level, on its own and in interaction with cognitive and behavioral levels, determines the quality of the disease-related experience and the personal meaning of illness.

It may be concluded that, in many patients, revealed affective (depressive and anxiety) symptoms are the result of poor adjustment to the disease, contributed to by general social frustration (including a low level of social support) and increased stress in combination with insufficient coping ability or the preference of unconstructive coping strategies (Wasserman, et al., 2002).

Successful overcoming of stressful situations, including DM itself and its consequences, is dependent on the patient's effective coping strategies. The importance of a rational, problem-focused coping style has been supported in a number of studies, and some researchers have indicated coping style as the main factor facilitating the patient's adjustment (Rose et al., 2002).

The importance of the "stress-coping" complex in relation to diabetic control is confirmed on one hand by the ability of stressful situations to lead to an increase of average blood glucose concentrations (Goldston, Kovacs, Obrosky, \& Iyengar, 1995; Wrigley \& Mayou, 1991), and on the other hand, by the ability of active problem-focused behavior to lead to better psychosocial and diabetes outcomes (Griffith,
Field, \& Lustman, 1990; Rose et al., 2002; Seiffge-Krenke \& Stemmler, 2003).

The patient's ability to cope with stressful situations gains importance in the light of the results of a study by Peyrot and McMurry (1992), who noted that stress was associated with poor glycemic control only in patients using ineffective coping strategies. In other words, effective coping can protect an individual from the adverse effects of stress. Thus, the effectiveness of coping behavior is connected to general psychosocial adjustment of DM patients and to their mental and physical health outcomes, making the assessment of coping styles necessary for adequate prevention of psychosocial disturbances, nonadherence, and metabolic decompensation in DM.

Of no lesser importance than the patients' way of coping with diabetes-related stress is their social environment. An increased risk of social frustration as a result of failure to satisfy one's social needs (Wasserman, 1995) and often stigmatization in DM persons is caused not only by "physical" aspects of the disease, but also by insufficient attention of society to the needs of DM patients, attempts to create in them a sense of inferiority, ignorance, etc. Perceived inadequacy of social support as one of the most important coping resources significantly reduces adjustment possibilities of the personality. Positive social support can act as a buffer, reducing the link between severe somatic pathology and depression (Connell et al., 1994), and also between stress and glycemic control (Griffith, et al., 1990).

The significance of social milieu is particularly prominent for children and adolescents (Hauser et al., 1990). Family conflicts, disregard for the child's needs and interests, insufficient attention to the disease management inevitably lead to metabolic decompensation and, when becoming a chronic condition, contributes to rapid development of long-term complications. Not only medical outcome, but also the consequent psychosocial adjustment is dependent on the family's health-promoting attitude towards the child's ailment. It is also important to take into account the fact that the disease in a child (adolescent) is a major stressor for the entire family, which, as a self-organizing system, should choose its own coping strategy.

Indirect evidence for the significance of constructive coping behavior comes from the research on the efficacy of coping skills trainings (Hampson et al., 2001), which are often included in standard diabetes educational programs. The positive effect of the latter as shown by research (Brown, 1992) is significant, although temporary. Knowledge of the diabetes self-care rules is a necessary though insufficient condition for a strict treatment adherence. This fact emphasizes the importance of personality-mediated disease perception and the attitude towards, which determine the patient's health behavior.

Actually, the subjective disease picture, as a diseaserelated cognitive-affective-behavioral complex that reflects its personal meaning for the patient, should be of first importance for the clinical psychologist (Lipowski, 1983; 
Luria, 1977; Nikolaeva, 1987; Wasserman \& Zaitsev, 1990). This is determined primarily by its integrated nature, including the following levels.

1. Cognitive level: The patient's conception of the disease (evaluation of its danger, conception of its nature, its causes and consequences, subjective prognosis and the possibility to influence its course, beliefs about efficacy of available treatment and personal ability to perform self-care procedures, etc.) .

2. Affective level: The patient's emotional reaction to the disease and its consequences. Fear, anxiety, depression, sorrow, guilt, resentment, and anger are all emotions the combination of which may occur at various stages of the realization of the disease and may be an entirely natural reaction to such a psycho-traumatic event. The intensity and persistence of negative emotions due to the ailment may reach clinically significant levels (depression, anxiety), the deleterious consequences of which are described above.

3. Behavioral level: This level includes diabetes selfcare, ways of coping with disease-related stressors, the manner of communication with medical personnel, extent of physical activity, changes in habits, etc.

The nature of personal disease picture depends both on its objective characteristics (its course, complication severity and vital risk, objective functional limitations caused by the disease, etc.) and the personality of the patient (the extent of her/his emotional stability, coping-style, personal value systems, social environment, socio-demographic characteristics, etc.).

On the other hand, the patient's attitude towards the disease has an effect on his/her somatic state. In particular, the intensity of depressive component within a personal disease picture significantly worsens prognosis as it manifests itself in the following phenomena:

1. On the cognitive level: perception of the hopelessness of one's state, personal helplessness, belief in one's "inadequacy," etc.;

2. On the emotional level: sadness, apathy, guilt, etc.;

3. On the behavioral level: gross disruptions of compliance, limitation of social contacts, and decrease in physical activity.

Thus, the result of the assessment of the degree and nature of social frustration, the patients' coping behavior and their attitude towards the disease can be fruitfully implemented in psycho-preventive work aimed at improving HRQoL.

\section{Methodological principles of health-related quality} of life assessment in diabetes mellitus

All the above-mentioned allows the conclusion that the HRQoL of DM1 patients is formed by interplay between variables of psychosocial and physical levels. Investigation and, if required, correction of the psychological component should be the principal concern of mental health specialists- clinical psychologists, psychiatrists and psychotherapistsacting in close cooperation with endocrinologists and other medical specialists.

Psychodiagnostic (both experimental and clinical) investigation in this case should be carried out with the tools (Wasserman \& Shchelkova, 2004) covering the following information:

1. The patient's current emotional state, dominant tendencies within emotional (neurosis-like) disturbance (e.g., anxiety-phobic, depressive-hypochondriac tendencies, etc.), symptoms of somatization, initial signs of psychological maladjustment. The ratio of somatogenic and psychogenic components in psychological dysfunction (when revealed).

2. Association between emotional disturbance, the patient's subjective model of the disease and healthrelated behavior-the personal disease picture.

3. The patient's way of coping with individually significant stressors including the disease itself, its physical and social consequences. Of importance is also information on mechanisms of psychological defense as a way to overcome anxiety.

4. The level of social frustration and in particular, degree and quality of social support.

In accordance to the required information, the psychologist working with diabetic patients should carry out comprehensive experimental-psychological investigations, including the following set of methods:

1. Several instruments or multi-scale questionnaires designed to measure the presence and severity of psychiatric symptoms, such as the Minnesota Multiphasic Personality Inventory (MMPI; Hathaway \& McKinley, 1951, 1967), the Symptom Check List90-Revised (SCL-90-R; Derogatis, 1983), The Hospital Anxiety and Depression Scale (HADS; Zigmond \& Snaith, 1983), State-Trait Anxiety Inventory (STAI; Spielberger, Gorsuch, Lushene, Vagg, \& Jacobs, 1983), the Beck Depression Inventory (BDI; Beck, Ward, Mendelson, Mock, \& Erbaugh, 1961), SelfRating Depression (SDS; Zung, 1965), etc.

2. Comprehensive instruments for the examination of cognitive, affective and behavioral components of disease perception. For example the Questionnaire for Psychological Diagnosis of Attitudes towards Disease (TATD; Wasserman, Iovlev, Karpova, \& Vuks, 2005), developed in the laboratory of clinical psychology of the V.M. Bekhterev Institute.

3. Measures of coping behavior (including the way of coping with disease-related stressors), for example, the Ways of Coping Questionnaire (WCQ; Folkman \& Lazarus, 1988), the COPE scale, (COPE; Carver, Scheier, \& Weintrub, 1989), the Coping Inventory for Stress Situations (CISS; Endler, \& Parker, 1990), the Zurich Questionnaire of Coping with Illness (ZKV; Sieber, Buddeberg, \& Wolf, 1991), etc. 
4. Measures of social frustration and social support, for example, the Social Support Questionnaire (SSQ; Sarason, Levine, Bashman, \& Sarason, 1983), the Interpersonal Support Evaluation List (ISEL; Cohen \& Hoberman, 1983), etc.

Information acquired using such an approach allow a holistic conception of the patient's psychological adjustment to DM, understanding of the possible causes of poor emotional adaptation, and identification of intervention targets. Where necessary, the battery can be expanded in accordance with the purposes of psycho-preventive intervention, in particular by personality questionnaires, neurocognitive assessment tools, "family diagnosis" techniques (examination of family relationships), projective measures for identification of unconscious conflicts and defense mechanisms, etc.

Undoubtedly, psychological assessment, especially in outpatient conditions should be carefully balanced between thoroughness of examination and limited time resources. A multidimensional psychological assessment of each DM1 patient irrespective of its potential benefit may be justified only in presence of evident adjustment impairment requiring psychological correction. In all other cases, necessary and sufficient would apparently be the use of time-saving screening instruments. Such are a multitude of HRQoL measures.

Application of HRQoL questionnaires provides preliminary information on the influence of the disease on the patient's satisfaction within various life-domains, and the illness impact on the patient's life. In the case of diabetes-specific quality of life (QoL), one can assess the impact of DM.

Currently there are many tools designed to measure diabetes-related QoL. For instance:

1. Audit of Diabetes-Dependent Quality of Life (ADDQoL; Bradley et al., 1999). This consists of 13 items and is designed to assess the influence of the disease on the patient's daily activity.

2. Diabetes-39 (D-39; Boyer \& Earp, 1997). This instrument consists of 39 items, permits the assessment of HRQoL in DM, it covers five dimensions of functioning: Energy and mobility, Diabetes control, Anxiety and worry, Social burden, and Sexual functioning.

3. Diabetes Health Profile (DHP-1, DHP-18; Meadows et al., 1996). It consists of 32 items, aimed at the assessment of HRQoL in DM patients requiring insulin replacement therapy, includes three scales: Psychological distress, Barriers to activity, and Disinhibited eating.

4. Problem Areas in Diabetes (PAID; Polonsky et al., 1995). This instrument consists of 20 items and is intended for the assessment of diabetes-related emotional distress.

5. Diabetes Quality of Life Measure (DQOL; Jacobson, Barofsky, Cleary, \& Rand, 1988). It consists of 46 items and is designed to assess HRQoL in DM1, primarily in youths. The questionnaire includes four scales: Life satisfaction, Diabetes impact, Worries about diabetes, and Social/vocational concerns.

6. Diabetes-Specific Quality-of-Life Scale (DSQOL; Bott, Mühlhauser, Overmann, \& Berger, 1998). This instrument consists of 64 items intended for the assessment HRQoL in DM1. The questionnaire includes a section covering individual treatment aims, a section covering satisfaction with treatment effectiveness, and six scales assessing the influence of DM1 on daily functioning: Social relations, Somatic complaints, Worries about the future, Leisure, Dietary limitations, and Treatment satisfaction.

There are several other instruments for diabetes-specific QoL assessment and the number is constantly growing. The advantage of applying diabetes-related QoL questionnaires is determined by the fact that these instruments:

1. Are specifically designed for this group of patients and with specifics of the disease and its potential impact on daily life taken into consideration;

2. Most of them are not time-consuming;

3. Allow preliminary assessment of the patient's functional limitations, psychological status and social functioning;

4. Allow identification of patients at risk for poor adjustment to the disease;

5. Generally have good face validity: their content is well understood by patients and does not cause them to consider themselves to be "mentally ill";

6. May be administered by medical personnel without the risk of being misinterpreted by patients and opposition to investigation;

7. When used by the physician in charge, these questionnaires permit some objectiveness in assessment of treatment effectiveness and enhance patient-provider communication;

8. In combination with clinical data, they can be used to assess efficacy of therapeutic measures.

The practical significance of HRQoL assessment is furthermore determined by the fact that the concept HRQoL can be fruitfully implemented in order to improve the cooperation between specialists of varying fields (physicians, psychologists, social workers).

It is also necessary to note that HRQoL assessment and even in-depth analysis of the patient's diabetes-specific problems (diet maintenance difficulty, fear of hypoglycemia, concerns about the influence of the disease on occupational functioning, mobility etc.) do not allow understanding of mechanisms underlying the empirically ascertained HRQoL. Validation of the majority of HRQoL assessment instruments in DM involves the attainment of significant correlations between objective measures of disease severity (the number of long-term complications, glycosylated hemoglobin concentration etc.) and indices of the patient's emotional state, the adequacy of perceived social support, and so on. Therefore, to determine the targets for further treatment and 
psychological interventions, it is necessary to clarify specific mechanisms involved in the formation of quantitative and qualitative characteristics identified with the use of a HRQoL questionnaire.

Assessment of HRQoL is but the first step in research into adaptation mechanisms of each individual patient in each specific circumstance; however, this step is of great significance, as it leads to the enhancement of patientphysician cooperation which is necessary for implementation of comprehensive treatment of DM patients.

\section{References}

Alexander, F. (1950). Psychosomatic medicine: Its principles and applications. New York: Norton.

Anderson, R.J. (1985). Is the problem of compliance all in our heads? Diabetes Education, 11, 31-34.

Anderson, R.J., Freedland, K.E., Clouse, R.E., \& Lustman, P.J. (2001). The prevalence of comorbid depression in adults with diabetes. A meta-analysis. Diabetes Care, 24, 1069-1078.

Barrett, E.J. (2004). Diabetes epidemic is a worldwide threat. Clinical Diabetes, 22, 47-48.

Beck, A.T., Ward, C.H., Mendelson, M., Mock, J., \& Erbaugh, J. (1961). An inventory for measuring depression. Archives of General Psychiatry, 4, 561-571.

Black, S.A., Markides, K.S., \& Ray, L.A. (2003). Depression predicts increased incidence of adverse health outcomes in older Mexican Americans with Type 2 diabetes. Diabetes Care, 26, 2822-2828.

Bott, U., Mühlhauser, I., Overmann, H., \& Berger, M. (1998). Validation of a Diabetes-Specific Quality-of-Life Scale for patients with Type 1 diabetes. Diabetes Care, 21, 757-769.

Boyer, J.G., \& Earp, J.A. (1997). The development of an instrument for assessing the quality of life of people with diabetes. Diabetes-39. Medical Care, 35, 440-453.

Bradley, C., Todd, C., Gorton, T., Symonds, E., Martin, A., \& Plowright, R. (1999). The development of an individualized questionnaire measure of perceived impact of diabetes on quality of life: The ADDQoL. Quality of Life Research, 8, 7991.

Brands, A.M., Biessels, G.J., de Haan, E.H., Kappelle, L.J., \& Kessels, R.P. (2005). The effects of type 1 diabetes on cognitive performance. A meta-analysis. Diabetes Care, 28, 726-735.

Brown, S.A. (1992). Meta-analysis of diabetes patient education research: Variations in intervention effects across studies. Research in Nursing \& Health, 15, 409-419.

Carver, S.C., Scheier, F.M., \& Weintrub, J.K. (1989). Assessing coping strategies: A theoretical based approach. Journal of Personality and Social Psychology, 56, 267-283.

Ciechanowski, P.S., Katon, W.J., \& Russo, J.E. (2000). Depression and diabetes: Impact of depressive symptoms on adherence, function, and costs. Archives of Internal Medicine, 160, 3278-3285.

Clouse, R.E., Lustman, P.J., Freedland, K.E., Griffith, L.S., McGill, J.B., \& Carney, R.M. (2003). Depression and coronary heart disease in women with diabetes. Psychosomatic Medicine, 65, 376-383.

Cohen, S., \& Hoberman, H.M. (1983). Positive events and social supports as buffers of life change stress. Journal of Applied Social Psychology, 13, 99-125.

Connell, C.M., Davis, W.K., Gallant, M.P., \& Sharpe, P.A. (1994). Impact of social support, social cognitive variables, and perceived threat on depression among adults with diabetes. Health Psychology, 13, 263-273.

de Groot, M., Anderson, R.J., Freedland, K.E., Clouse, R.E., \& Lustman, P.J. (2001). Association of depression and diabetes complications: a meta-analysis. Psychosomatic Medicine, 63, 619-630.

Delamater, A.M., Jacobson, A.M., Anderson, B., Cox, D., Fisher, L., Lustman, P., Rubin, R., \& Wysocki, T. (2001). Psychosocial Therapies Working Group: Psychosocial therapies in diabetes: Report of the Psychosocial Therapies Working Group. Diabetes Care, 24, 1286-1292.

Derogatis, L.R. (1983). SCL-90-R Administration, Scoring, Procedures Manual II for the Revised Version ( $2^{\text {nd }}$ ed). Towson, MD: Clinical Psychometric Research.

Dunbar, F. (1948). Psychosomatic diagnosis. New York: Harper \& Row.

Dunn, S.R., \& Turtle, J.R. (1981). The myth of the diabetic personality. Diabetes Care, 4, 640-646.

Eaton, W.W., Armenian, H., Gallo, J., Pratt, L., \& Ford, D.E. (1996). Depression and risk for onset of Type II diabetes. A prospective population-based study. Diabetes Care, 19, 1097-1102.

Endler, N.S., \& Parker, J.D.A. (1990). Coping Inventory for Stressful Situations (CISS): Manual. Toronto, Canada: Multi-Health Systems.

Folkman, S., \& Lazarus, R. (1988). Manual for the Ways of Coping Questionnaire. Redwood City, CA: Mind Garden.

Glasgow, R.E., \& Anderson, R.M. (1999). In diabetes care, moving from compliance to adherence is not enough. Something entirely different is needed. Diabetes Care, 22, 2090-2092.

Glasgow, R.E., Ruggiero, L., Eakin, E.G., Dryfoos, J., \& Chobanian, L. (1997). Quality of life and associated characteristics in a large national sample of adults with diabetes. Diabetes Care, 20, 562-567.

Glasgow, R.E., Toobert, D.J., \& Gillette, C.D. (2001). Psychosocial barriers to diabetes self-management and quality of life. Diabetes Spectrum, 14, 33-41.

Goldston, D.B., Kovacs, M., Obrosky, D.S., \& Iyengar, S. (1995). A longitudinal study of life events and metabolic control among youths with insulin-dependent diabetes mellitus. Health Psychology, 14, 409-414.

Griffith, L.S., Field B.J., \& Lustman, P.J. (1990). Life stress and social support in diabetes: Association with glycaemic control. International Journal of Psychiatry in Medicine, 20, 365-372.

Grigsby, A.B., Anderson, R.J., Freedland, K.E., Clouse, R.E., \& Lustman, P.J. (2002). Prevalence of anxiety in adults with diabetes: A systematic review. Journal of Psychosomatic Research, 53, 1053-1060. 
Hampson, S.E., Skinner, T.C., Hart, J., Storey, L., Gage, H., Foxcroft, D., Kimber, A., Shaw, K., \& Walker, J. (2001). Effects of educational and psychosocial interventions for adolescents with diabetes mellitus: A systematic review. Health Technology Assessment, 5, 71-79.

Harris, M.A., \& Lustman, P.J. (1998). The psychologist in diabetes care. Clinical Diabetes, 16, 91-93.

Hathaway, S.R., \& McKinley, J.C. (1951, 1967 Rev.). The Minnesota Multiphasic Personality Inventory manual. New York. Psychological Corporation.

Hauser S.T., Jacobson A.M., Lavori P., Wolfsdorf J.I., Herskowitz R.D., Milley J.E., Bliss R., Wertlieb D., \& Stein J. (1990). Adherence among children and adolescents with insulindependent diabetes mellitus over a 4-year follow-up. II: Immediate and long term linkages with the family milieu. Journal of Pediatric Psychology, 15, 527-542.

Heisler, M., Bouknight, R.R., Hayward, R.A., Smith, D.M., \& Kerr, E.A. (2002). The relative importance of physician communication, participatory decision making, and patient understanding in diabetes self-management. Journal of General Internal Medicine, 17, 243-252.

Herpertz, S., Albus, C., Lohff, S., Michalski, K., Masrour, M., Lichtblau, K., Kohle, K., Mann, K., \& Senf, W. (2000). Comorbidity of diabetes mellitus and eating disorders. A comparison of psychological features of eating disordered and non-eating disordered patients with diabetes mellitus [Article in German]. Psychotherapie, Psychosomatik, medizinische Psychologie, 50, 161-168.

Jacobson, A.M., Barofsky, I., Cleary, P., \& Rand, L. (1988). Reliability and validity of a diabetes quality-of-life measure for the diabetes control and complications trial (DCCT). Diabetes Care, 11, 725-732.

Jacobson, A.M., de Groot, M., \& Samson, J.A. (1997). The effects of psychiatric disorders and symptoms on quality of life in patients with Type I and Type II diabetes mellitus. Quality of Life Research, 6, 11-20.

Jackson, J.L., \& Kroenke, K. (1999). Difficult patient encounters in the ambulatory clinic: clinical predictors and outcomes. Archives of Internal Medicine, 159, 1069-1075.

Katon, W.J. (2003). Clinical and health services relationships between major depression, depressive symptoms, and general medical illness. Biological Psychiatry, 54, 216-226.

Kohen, D., Burgess, A. P., Catalan, J., \& Lant, A. (1998). The role of anxiety and depression in quality of life and symptom reporting in people with diabetes mellitus. Quality of Life Research, 7, 197-204.

Korkina, M.V., \& Elfimova, E.V. (2004). Psichogennosomatogennye vzaimootnosheniya pri sacharnom diabete [Psychogenic and somatic interactions in diabetes mellitus]. Zh Nevrol Psikhiatr Im SS Korsakova, 104(11), 25-28.

Lipowski, Z.J. (1983). Psychosocial reactions to physical illness. Canadian Medical Association Journal, 128, 1069-1072.

Lloyd, C.E., \& Orchard, T.J. (1999). Physical and psychological well-being in adults with Type 1 diabetes. Diabetes Research and Clinical Practice, 44, 9-19.
Luria, R.A. (1977). Vnutrennyaya kartina bolezni i iatrogennye zabolevaniya [Subjective illness picture and iatrogenic diseases] ( $4^{\text {th }}$ ed.). Moscow: Meditzina.

Lustman, P.J. (1988). Anxiety disorders in adults with diabetes mellitus. Psychiatric Clinics of North America, 11, 419-432.

Lustman, P.J., Anderson, R.J., Freedland, K.E., de Groot, M., Carney, R.M., \& Clouse, R.E. (2000). Depression and poor glycaemic control: A meta-analytic review of the literature. Diabetes Care, 23, 434-442.

Lustman, P.J., \& Clouse, R.E. (2002). Treatment of depression in diabetes: Impact on mood and medical outcome. Journal of Psychosomatic Research, 53, 917 -924.

Lustman, P.J., Clouse, R.E., Ciechanowski, P.S., Hirsch, I.B., \& Freedland, K.E. (2005). Depression-related hyperglycaemia in Type 1 diabetes: A mediational approach. Psychosomatic Medicine, 67, 195-199.

Lustman, P.J., Griffith, L.S., \& Clouse, R.E. (1988). Depression in adults with diabetes. Results of 5-year follow-up study. Diabetes Care, 11, 605-612.

Meadows, K., Steen, N., McColl, E., Eccles, M., Shiels, C., Hewison, J., \& Hutchinson, A. (1996). The Diabetes Health Profile (DHP): A new instrument for assessing the psychosocial profile of insulin requiring patients-development and psychometric evaluation. Quality of Life Research, 5, 242-254.

Mollema, E.D., Snoek, F.J., Ader, H.J., Heine, R.J., \& van der Ploeg, H.M. (2001). Insulin-treated diabetes patients with fear of self-injecting or fear of self-testing. Psychological comorbidity and general well-being. Journal of Psychosomatic Research, 51, 665-672.

Mooy, J.M., de Vries, H., Grootenhuis, P.A., Bouter, L.M., \& Heine, R.J. (2000). Major stressful life events in relation to prevalence of undetected type 2 diabetes: The Hoorn Study. Diabetes Care, 23, 197-201.

Nikolaeva V.V. (1987). Vliyanie chronicheskoy bolezni na psichiku [The influence of chronic disease on the psyche]. Moscow: Izdatelstvo MGU (Moscow State University).

Northam, E.A., Anderson, P.J., Werther, G.A., Warne, G.L., \& Andrewes, D. (1999). Predictors of change in the neuropsychological profiles of children with Type 1 diabetes 2 years after disease onset. Diabetes Care, 22, 1438-1444.

Peyrot M., \& McMurry, J.F.Jr. (1992). Stress buffering and glycaemic control. The role of coping style. Diabetes Care, 15, 842-846.

Polonsky, W.H. (2000). Understanding and assessing diabetesspecific quality of life. Diabetes Spectrum, 13, 36-41.

Polonsky, W.H., Anderson, B.J., Lohrer, P.A., Welch, G., Jacobson, A.M., \& Schwartz, C. (1995). Assessment of diabetes-specific distress. Diabetes Care, 18, 754-760.

Polonsky, W.H., Davis, C.L., Jacobson, A.M., \& Anderson, B.J. (1992). Correlates of hypoglycaemic fear in type I and type II diabetes mellitus. Health Psychology, 11, 199-202.

Rose, M., Fliege, H., Hildebrandt, M., Schirop, T., \& Klapp, B.F. (2002). The network of psychological variables in patients with diabetes and their importance for quality of life and metabolic control. Diabetes Care, 25, 35-42. 
Rubin, R.J., Altman, W.M., \& Mendelson, D.N. (1994). Health care expenditures for people with diabetes mellitus. Journal of Clinical Endocrinology and Metababolism, 78, 809A-809F.

Rubin, R.R., \& Peyrot M. (2002). Was Willis right? Thoughts on the interaction of depression and diabetes. Diabetes/Metabolism Research and Reviews, 18, 173-175.

Rubin, R.R., Ciechanowski, P., Egede, L.E., Lin, E.H., \& Lustman, P.J. (2004). Recognizing and treating depression in patients with diabetes. Current Diabetes Reports, 4, 119-125.

Sarason, I.G., Levine, H.M., Bashman, R.B., \& Sarason, B.R. (1983). Assessing social support: The Social Support Questionnaire. Journal of Personality and Social Psychology, 44, 127-139.

Schade, D.S., \& Burge, M.R. (1995). Brittle diabetes: Etiology and treatment. Advances in Endocrinology and Metabolism, 6, 289-319.

Schade, D.S., Eaton, R.P., Drumm, D.A., \& Duckworth, W.C. (1985). A clinical algorithm to determine the etiology of brittle diabetes. Diabetes Care, 8, 5-11.

Seiffge-Krenke, I., \& Stemmler, M. (2003). Coping with everyday stress and links to medical and psychosocial adaptation in diabetic adolescents. Journal of Adolescent Health, 33(3), 180188.

Sieber, M., Buddeberg, C., \& Wolf, C. (1991). Reliabilitat und Validitat des Zürcher Fragebogens zur Krankheitsverarbeitung (ZKV-R) [Reliability and validity of the Zurich Questionnaire of Coping with Illness]. Schweizer Archiv für Neurologie und Psychiatrtrie, 142, 553-67.

Skinner, T.C., \& Hampson, S.E. (2001). Personal models of diabetes in relation to self-care, well-being, and glycaemic control. A prospective study in adolescence. Diabetes Care, 24, 828-833.

Skinner, T.C., John, M., \& Hampson, S.E. (2000). Social support and personal models of diabetes as predictors of self-care and well-being: a longitudinal study of adolescents with diabetes. Journal of Pediatric Psychology, 25, 257-267.

Spielberger, C. D., Gorsuch, R. L., Lushene, T. E., Vagg, P. R., \& Jacobs, G. A. (1983). Manual for the State-Trait Anxiety Inventory. Palo Alto, CA: Consulting Psychologists Press.

Surwit, R.S., \& Schneider, M.S. (1993). Role of stress in the etiology and treatment of diabetes mellitus. Psychosomatic Medicine, 55, 380-393.

Talbot, F., \& Nouwen, A. (2000). A review of the relationship between depression and diabetes in adults: Is there a link? Diabetes Care, 23, 1556-1562.

Talbot, F., Nouwen, A., Gingras, J., Belanger, A., \& Audet, J. (1999). Relations of diabetes intrusiveness and personal control to symptoms of depression among adults with diabetes. Health Psychology, 18, 537-542.

Toljamo, M., \& Hentinen, M. (2001). Adherence to self-care and glycaemic control among people with insulin-dependent diabetes mellitus. Journal of Advanced Nursing, 34, 780-786.
Wales, J.K. (1995). Does psychological stress cause diabetes? Diabetic Medicine, 12, 109-112.

Wasserman, L.I. (1995). Psichodiagnosticheskaya shkala dlia otzenki urovnia sotzialnoy frustrirovannosty [A psychodiagnostic scale for social frustration assessment]. The Bekhterev Review of Psychiatry and Medical Psychology, 2, 113-122.

Wasserman, L.I., Gromov, S.A., Mikhailov, V.A., Lynnik, S.D., \& Flerova, I.L. (2002). Concepts of rehabilitation and quality of life: Their continuity and differences in modern approaches. International Journal of Mental Health, 31, 24-37.

Wasserman, L.I., Iovlev, B.V., Karpova, E.B., \& Vuks, A.Ya. (2005). Psichologicheskaya diagnostika otnosheniya $k$ bolezni [Psychological diagnosis of attitude towards disease.] St.Petersburg: V.M. Bekhterev Psychoneurological Research Institute.

Wasserman, L.I., \& Shchelkova O.Yu. (2004). Meditzinskaya psichodiagnostica: teoriya, praktika i obucheniye [Medical psychodiagnostics: Introduction to theory, practice and training]. Moscow, St. Petersburg: Akademia, Filologicheskiy facultet SPbGU (Saint Petersburg State University: Faculty of Philology).

Wasserman, L.I., \& Trifonova, E.A. (2004). Quality of life and the structure of neurosis-like symptomatology in persons with insulin-dependent diabetes mellitus. International Journal of Mental Health, 33, 47-57.

Wasserman, L.I, \& Zaitsev, V.P. (Eds.) (1990). Psichologicheskaya diagnostika otnosheniya $k$ bolezni pri nervno-psichichecskoy i somaticheskoy patologii [Psychological diagnosis of attitude towards disease in neuro-psychiatric and somatic disorders]. Leningrad: V.M. Bekhterev Psychoneurological Research Institute.

Wredling, R.A., Theorell, P.G., Roll, H.M., Lins, P.E., \& Adamson, U.K. (1992). Psychosocial state of patients with IDDM prone to recurrent episodes of severe hypoglycaemia. Diabetes Care, 15, 518-521.

Wrigley, M., \& Mayou, R. (1991). Psychosocial factors and admission for poor glycaemic control: a study of psychological and social factors in poorly controlled insulin dependent diabetic patients. Journal of Psychosomatic Research, 35, 335-343.

Zhang, X., Norris, S. L., Gregg, E. W., Cheng, Y. J., Beckles, G., \& Kahn, H.S. (2005). Depressive symptoms and mortality among persons with and without diabetes. American Journal of Epidemiology, 161, 652-660.

Zigmond, A.S., \& Snaith, R.P. (1983). The Hospital Anxiety and Depression Scale. Acta Psychiatrica Scandavica, 67, 361-70.

Zung, W.W.K. (1965). A self-rating depression scale. Archives of General Psychiatry 12, 63-70.

Received, June, 24, 2005 Review received, November, 20, 2005 Accepted, December, 27, 2005 